\title{
Designing with Color in the Early Childhood Education Classroom: A Theoretical Perspective
}

\author{
Marilyn Read \\ Oregon State University, Corvallis, Oregon, USA \\ Email: marilyn.read@oregonstate.edu
}

How to cite this paper: Read, M. (2019). Designing with Color in the Early Childhood Education Classroom: A Theoretical Perspective. Creative Education, 10, 1070-1079. https://doi.org/10.4236/ce.2019.106080

Received: March 25, 2019

Accepted: June 9, 2019

Published: June 12, 2019

Copyright $\odot 2019$ by author(s) and Scientific Research Publishing Inc. This work is licensed under the Creative Commons Attribution International License (CC BY 4.0).

http://creativecommons.org/licenses/by/4.0/

\begin{abstract}
Early childhood education and care centers provide young children with opportunities to explore, create, reflect, experiment, and learn in the classroom environment. Theorists of human development have proposed theories, paradigms, models and ideologies regarding children's relationships with the social and physical environment. The physical layout of the early childhood education classroom is related to the center's theoretical or ideological perspective. For every theoretical model and teaching perspective, the designed environment will play a role in the quality of children's experiences in the classroom. The optimally-designed classroom space offers children a setting for exploration, reflection, and learning through the use and application of design principles and elements. The objective of this paper is to connect the concepts from the interior design field with the concepts from early childhood education perspectives on best practices for the design of early childhood education classrooms. Current research on color preference is presented, followed by an analysis of color in early childhood education classrooms. A color questionnaire is provided to assist teachers with the use of color as a design tool in their classrooms.
\end{abstract}

\section{Keywords}

Color, Early Childhood Education, Interior Design, Classroom Design

\section{Introduction}

Early childhood education and care centers provide young children with opportunities to explore, create, reflect, experiment, and learn in the classroom environment. Theorists of human development, including Dewey (1934), Bronfenbrenner (2005), Montessori (1967), Piaget (1959), Erikson (1963), Gibson 
(1979), and Vygotsky (1978) have proposed theories, paradigms, models and ideologies regarding children's relationships with the social and physical environment. Based on these theoretical approaches, a teaching model continuum of learning for young children would illustrate child-centered active learning models at one end, project-centered models at the center of the continuum, and teacher-directed instruction models located at the other end. The physical layout of early childhood education and care centers is related to the center's theoretical or ideological perspective whether that is an active learning perspective with play as a teaching approach, a thematic teaching approach, or a directed-instruction approach. For every theoretical model and teaching perspective, the designed environment will play a role in the quality of children's experiences in the classroom. The designed classroom space offers children opportunities for exploration, reflection, and learning by the use and application of design principles and elements.

Early childhood classrooms are rich and complex in their design and in their meaning to young children. Therefore, it is important to connect the concepts from the interior design field with the concepts from early childhood education perspectives on best practices for the design of early childhood education classrooms. Children's experiences in the designed environment are impacted by a classroom's myriad design elements and principles which include the circulation, spatial layout, degree of enclosure, material, color, and lighting of the space (Barrett, Davies, Zhang, \& Barrett, 2015; Jalil, Yunus, \& Said, 2012). The focus of this paper is on the use of color, a design element, in the early childhood education classroom and the association with current research on color preference.

\section{Background}

Children and adults respond to color in a myriad of ways. Findings from empirical studies include, among others, the impact the color red had on knowledge retrieval for high school students (Gnambs, Appel, \& Kaspar, 2015). University students found warm colors to be attractive in the environment (Hidayetoglu, Yildirim, \& Akalin, 2012); and young preschool children benefited from bright color cues for a spatial reasoning task (Joh \& Spivey, 2012). These studies revealed that color is a design element that acts as an influencing factor for a variety of human/environment interactions. These studies focus on diverse environmental variables without a clear direction of which hue, value, or chroma may be the optimal color for use in the early childhood environment. Recent research by Palmer and Schloss (2010) focuses on the primacy of color preference. The findings from the initial studies are discussed in the next section.

Empirical research in color preference has focused predominantly on individual reactions to stimuli in the environment (Beke, Kutas, Kwak, Young Sung, Park, \& Bodrogi, 2008). This approach to understanding color preference is limited for designing community spaces. Palmer and Schloss (2010) defined color preference as "how much people like different colors" (Palmer \& Schloss, 2015: 
p. 1). The Ecological Valence Theory (Palmer \& Schloss, 2010; Palmer \& Schloss, 2015), proposed by Palmer and Schloss (2010) comprises 8 hues (Red, Orange, Yellow, Yellow-Green, Blue-Green, Purple, Cyan, and Green) with varied by saturation and lightness levels with 32 distinct colors. Overall study participants preferred colors on the blue-yellow scale that were bluer; on the saturation scale, colors that were highly saturated; and on the light/dark scale colors that were lighter in value. It should be noted that participants in the study were adults. Colors that were less preferred included dark orange, a brown appearance, and dark yellow that appeared as an olive color (Palmer \& Schloss, 2010; Palmer \& Schloss, 2015). Their findings reveal that that people associate the colors they preferred with environmental objects (Palmer \& Schloss, 2010). The association of the valence of a color focuses on how much an individual likes an object. For example, the color blue connotes images of water and the sky, which are generally positive associations for people. Additionally, the research with the Ecological Valence Theory illustrates the importance of harmonious color. Schloss and Palmer (2017) described individual differences in color preferences for design; however, an important factor for understanding preferences was color harmony, meaning colors experienced in combination with other colors.

Research with infant color preference has found that infants prefer hues or colors relative to white (Zemach \& Teller, 2007). The infants viewed two colors next to each other and the preferred color was determined by the length of time an infant focused on a color along with which color the infant viewed first (Zemach \& Teller, 2007). Cones in the eye which are sensitive to light wavelengths may contribute to infant color preference. Franklin and others (2010) looked at the Short, Medium, and Long cones, sensitive to different wavelengths of light, that determine color vision as it relates to color preference (Franklin, Bevis, Ling, \& Hurlbert, 2010). They concluded that the cone contrasts interacted with the observed color and the background to explain infant color preference for red as compared with green. Therefore, understanding color preference may have a biological component. Pitchford, Davis, and Scerif (2009) found that there was a relationship between color preference and young children's acquisition of color terms. An earlier study by Pitchford and Mullen (2005) found that brown and grey were not preferred colors by young children which may be related to their vocabulary when learning color names. Clearly, hue, value, and saturation are important attributes when considering children's environments. The next section evaluates the application of color in the preschool environment.

Early childhood education classrooms are complex spaces. The spaces reflect the theoretical perspectives and applied practical realities of the centers. Two useful academic resources for recommendations for the optimal design of center environments include Thinking Critically About Environments for Young Children: Bridging Theory \& Practice (2014), edited by Lisa P. Kuh and Caring Spaces, Learning Places: Children's Environments That Work (2017) by Jim Greenman, edited by Mike Lindstrom. Both resources approach the design of 
children's environments from a holistic lens. In particular, the authors examined the changes in the design of early childhood education environments over the past few decades. The selected concepts of the designed interior classroom are general rather than specific in nature. Therefore, it is a challenge for teachers to analyze and synthesize interior design concepts and design details for their own classrooms. Color is not a central concept for design in either resource.

The purpose of this report paper is to narrow the focus of the designed environment to illustrate optimal application of color as a design element in the early childhood education classroom. To evaluate color within the early childhood education classroom, teachers, staff, and students review the existing colors and materials in the space. The first step is to separate each activity setting, for example, reading, large motor play, etc., thereby focusing on the focal point of the activity setting. Describe the color in the activity setting. The second step is to photograph the settings in the early childhood education classroom. Describe how the colors relate to each other and the interrelationships of the design elements between two or more areas. It is useful to take photographs of the classroom and the designed elements from different heights, multiple angles and different perspectives. Photographs help to reveal color application and color value by focusing on one specific area within the frame.

The third step is to complete the color questionnaire (see Appendix 1) which is proposed as a tool for teachers to use to design the classroom environment. The fourth step is to reflect on the findings from the visual research completed by teachers, staff, and children. The fifth step is to determine how color in the environment is supportive of an optimal design of the early childhood education classroom. In a classroom that does not have effective use of color, consider adapting lighting and finishes in the design to create a harmonious environment. Changes can be made with addition of fabric, posters, or murals to adapt the designed environment.

The next section illustrates case studies of color in the early childhood education classroom environment with photographs of existing classrooms.

Case Studies of Color in Early Childhood Education Classrooms

Figure 1 illustrates an environment with a focal color orange on the wall. The lighter orange is located on the back of the wall, framing the cabinetry. Above the light orange section, a darker orange is painted on the soffit area where lighting is located. The cabinetry, horizontal work surface, and flooring are light in value with neutral colors. The orange hue provides an area for definition for children as the location of water to wash their hands and clean up their work areas. The sink is also emphasized with contrast of value on the floor with a dark rectangle as an identifier for children to use the sink. The focal area is contrasted by using a neutral color on the wall above the cubbies/individual storage spaces. Additionally, the cubbies are neutral of natural wood finish which adds visual contrast to the orange wall section.

Figure 2 illustrates separation of space with brightly hued low partitions. The 
partitions are a focal point because they are anchored against neutral backgrounds on the floor and the walls. The colors of the partitions are bright; therefore, they are a focal point in the image. They clearly define the activity areas in the space from the reading and writing area in red, the manipulative play section in red, yellow and blue, and the dramatic play section against the wall and sectioned off with the yellow partition. Flooring variety with carpet and linoleum also helps to define the settings for the three activity areas.

In Figure 3, color is used sparingly; however, the location where it is used is effective for adding contrast and interest to the space. The colors of the chairs are bright and warm, red and yellow with high saturation. The tables are dark blue which contrasts well with the white cabinetry on the back wall as well as the white storage units on the left side of the space. The blue frame around the door helps to define the circulation of the space with clear access into the hall area. The flooring has random tiles of bright colors, yellow and red.

Figure 4 and Figure 5 show classrooms that are visually over stimulating with the use of color, texture and pattern. This is a common occurrence because the open setting provides visual stimuli of many different elements from the planes, ceiling, wall, and floor; to work surfaces and furniture; to the display areas. It is not uncommon for early childhood education classrooms to have a visually over stimulating appearance.

Figure 4 has several layers of display that are located on the walls. These show shapes with color, fish counting with goldfish bowls, illustrations, and letters with animal images in color. So many different shapes and colors on the walls make it difficult for the eye to focus on one particular element of the display projects and materials. The colorful curtains and chairs add to the visually over stimulating environment. Focusing on two to three areas for bright color would help children to focus their attention on display materials and play materials.

Figure 5 illustrates a large early childhood education classroom with a large-scale loft. The black and white checkerboard flooring creates high contrast with visually stimulating pattern of light and dark squares. The floor plane is important when designing spaces. This contrast may be over-stimulating for young children. The yellow loft with its patterns of yellow lines, the yellow cubbies, and the display materials on the walls combine together to result in a visually over stimulating classroom.

Figure 6 displays an interior classroom with wall color using light and dark values of blue-green. The light blue-green wall is an effective background for children's art work. The dark blue-green wall and the dark absorb light, creating a dark environment. Creating a lighter floor plane or wall plane would improve the use of color in this classroom.

The interior classroom image in Figure 7 shows use of wall color with yellow, aqua, purple-blue, and orange. The values of the colors are light. Additionally, there is an abundance of natural light that balances the perception of the colors.

Figure 8 shows the interior of two different early childhood education class- 
rooms. The space on the left has a focal wall of green for the sink and for storage. The space on the right shows the use of blue for the wall color. Color is used in both classrooms as a focal point for young children. Both colors are visible through the window.

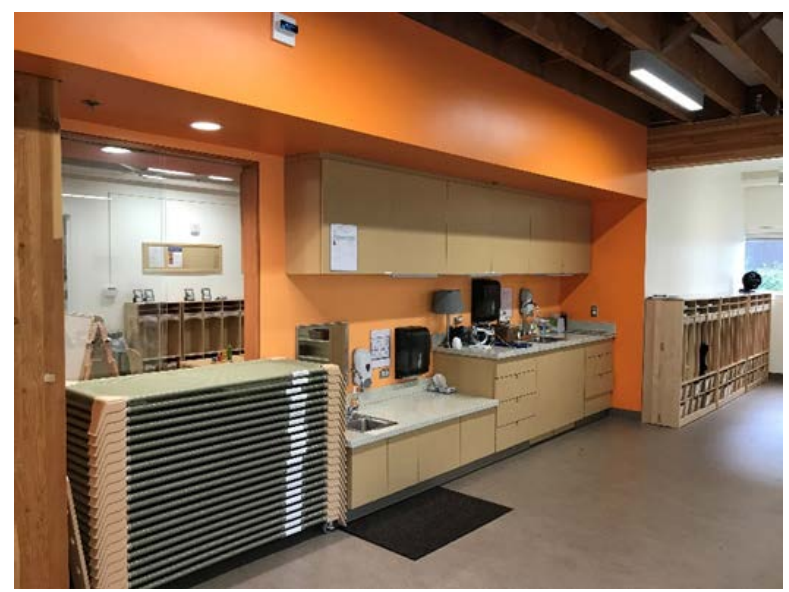

Figure 1. Interior classroom with orange wall and contrasting floor design.

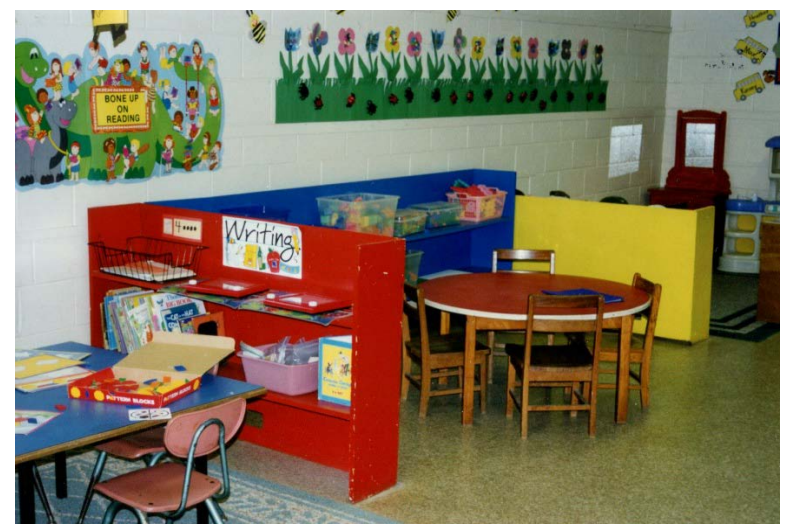

Figure 2. Brightly hued partitions define three different activity areas in this classroom.

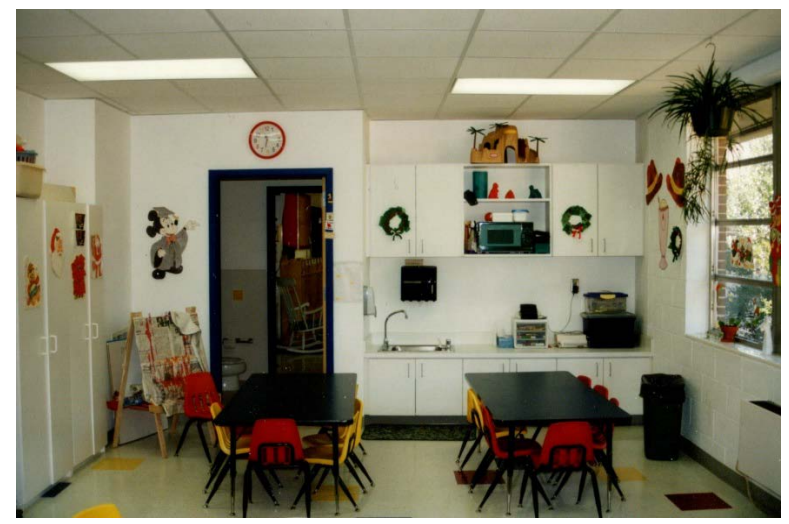

Figure 3. Color is used minimally in this classroom on furniture and door casing. 


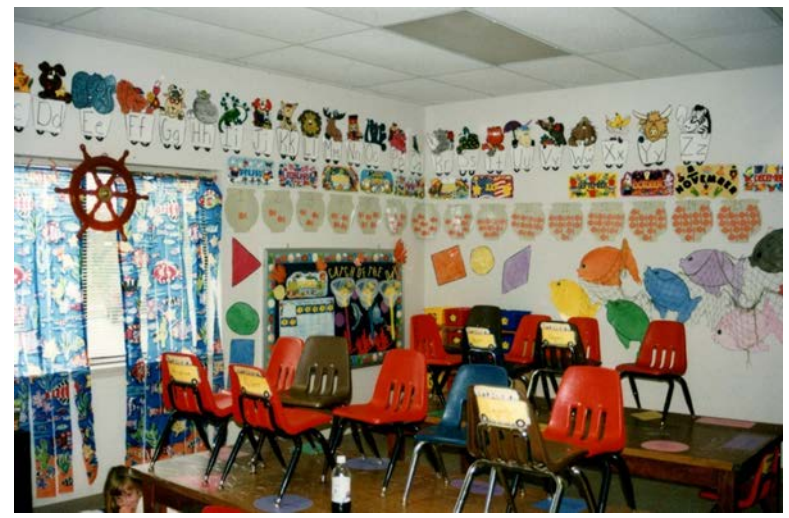

Figure 4. Overstimulating interior with multiple displays.

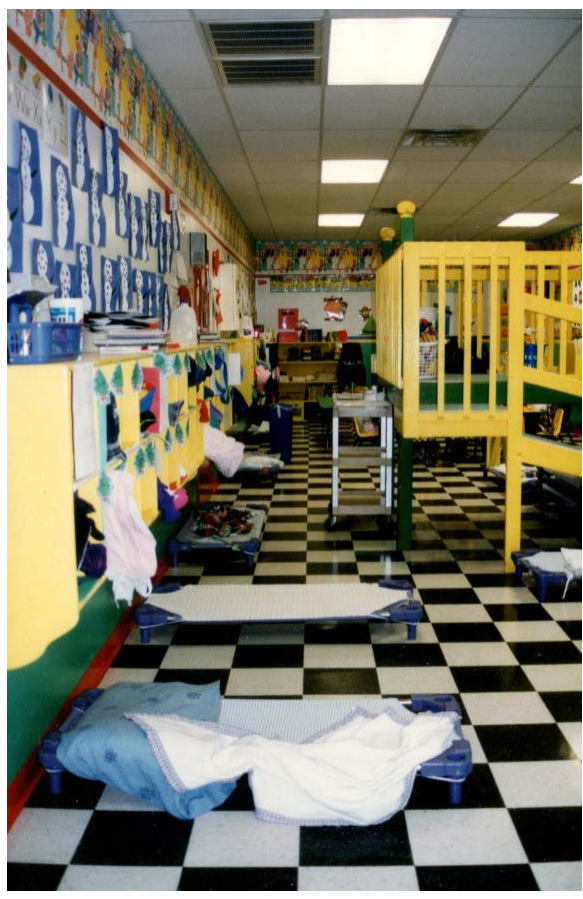

Figure 5. Over stimulating classroom with pattern and color.

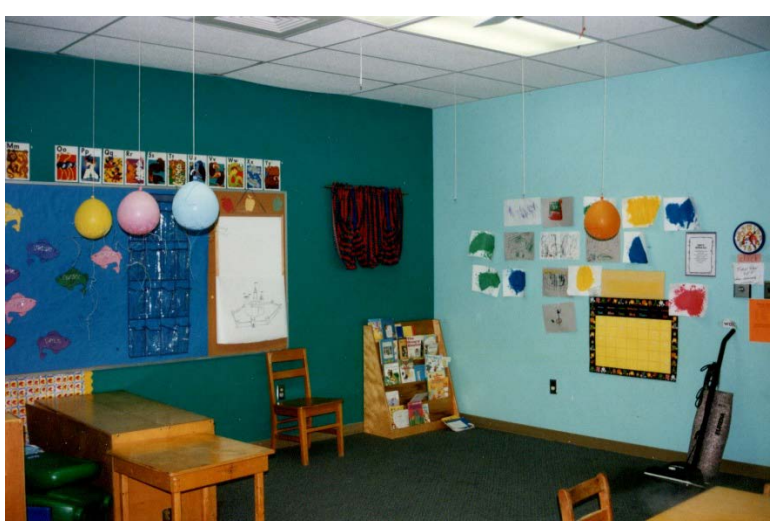

Figure 6. Light and dark values of blue-green with a dark floor. 


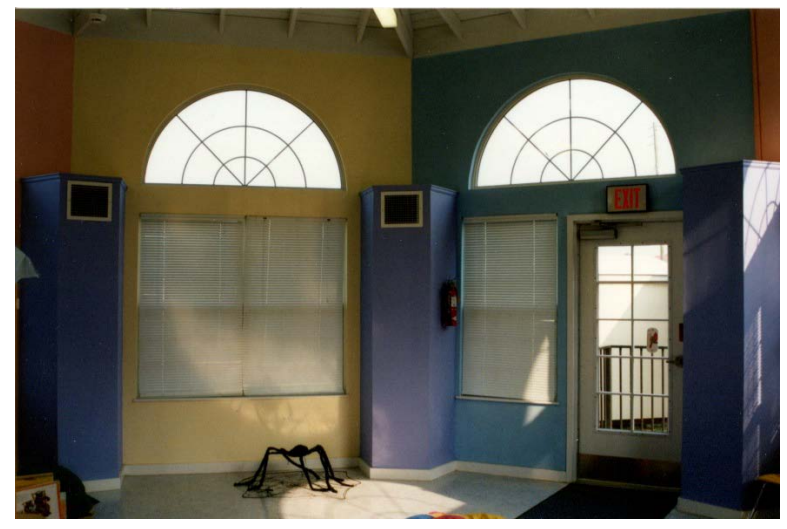

Figure 7. Wall colors with natural light.

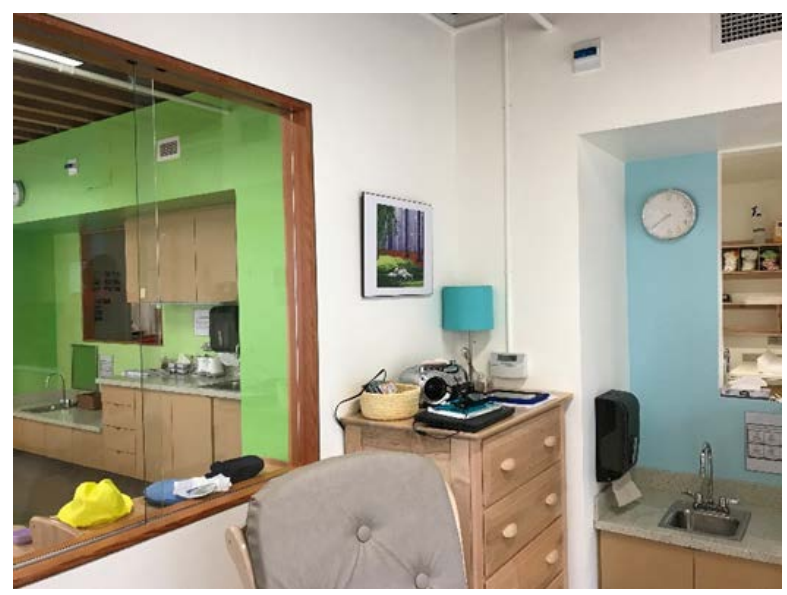

Figure 8. Two different wall colors, both visible through window.

\section{Conclusion}

Color is an important design element that contributes to the aesthetic qualities of the early childhood education classroom. Balancing application of color within the classroom helps children by offering them a focal point for an activity area. Careful consideration of how color's hue, value, and brightness affect the interior of the classroom benefits children's experiences in the space. A harmonious classroom environment that balances color and other design elements can be achieved with small changes in a designed environment. In conclusion, color is a complex design element with the potential to enhance a classroom environment for an optimal experience for young children.

\section{Conflicts of Interest}

The author declares no conflicts of interest regarding the publication of this paper.

\section{References}

Barrett, P., Davies, F., Zhang, Y., \& Barrett, L. (2015). The Impact of Classroom Design on Pupils' Learning: Final Results of a Holistic, Multi-Level Analysis. Building and En- 
vironment, 89, 118-133. https://doi.org/10.1016/j.buildenv.2015.02.013

Beke, L., Kutas, G., Kwak, Y., Young Sung, G., Park, D. S., \& Bodrogi, P. (2008). Color Preferences of Aged Observers Compared to Young Observers. Color Research \& Application, 33, 381-394. https://doi.org/10.1002/col.20434

Bronfenbrenner, U. (2005). Making Human Beings Human: Bioecological Perspectives on Human Development. Thousand Oaks, CA: Sage.

Dewey, J. (1934). Art as Experience. New York: Minton, Balch \& Company.

Erikson, E. (1963). Childhood and Society. New York: Norton \& Co.

Franklin, A., Bevis, L., Ling, Y., \& Hurlbert, A. (2010). Biological Components of Color Preference in Infancy. Developmental Science, 13, 346-354. https://doi.org/10.1111/j.1467-7687.2009.00884.x

Gibson, J. J. (1979). The Ecological Approach to Visual Perception. Boston, MA: Houghton Mifflin.

Gnambs, T., Appel, M., \& Kaspar, K. (2015). The Effect of the Color Red on Encoding and Retrieval of Declarative Knowledge. Learning and Individual Differences, 42, 90-96. https://doi.org/10.1016/j.lindif.2015.07.017

Hidayetoglu, M. L., Yildirim, K., \& Akalin, A. (2012). The Effects of Color and Light on Indoor Way Finding and the Evaluation of the Perceived Environment. Journal of Environmental Psychology, 32, 50-58. https://doi.org/10.1016/j.jenvp.2011.09.001

Jalil, N. A., Yunus, R. M., \& Said, N. S. (2012). Environmental Colour Impact upon Human Behavior: A Review. Procedia-Social and Behavioral Sciences, 35, 54-62. https://doi.org/10.1016/j.sbspro.2012.02.062

Joh, A. S., \& Spivey, L. A. (2012). Colorful Success: Preschoolers' Use of Perceptual Color Cues to Solve a Spatial Reasoning Problem. Journal of Experimental Child Psychology, 113, 523-534. https://doi.org/10.1016/j.jecp.2012.06.012

Montessori, M. (1967). The Discovery of the Child. New York: Ballantine Books.

Palmer, S. E., \& Schloss, K. B. (2010). An Ecological Valence Theory of Human Color Preference. Proceedings of the National Academy of Sciences of the United States of America: Psychological and Cognitive Sciences, 107, 8877-8882. https://doi.org/10.1073/pnas.0906172107

Palmer, S. E., \& Schloss, K. B. (2015). Color Preference. In Encyclopedia of Color Science and Technology (pp. 1-7). New York: Springer Science. https://doi.org/10.1007/978-3-642-27851-8_70-13

Piaget, J. (1959). The Language and Thought of the Child. New York: Routledge.

Pitchford, N. J., \& Mullen, K. T. (2005). The Role of Perception, Language, and Preference in the Developmental Acquisition of Basic Color Terms. Journal of Experimental Child Psychology, 90, 273-302. https://doi.org/10.1016/j.jecp.2004.12.005

Pitchford, N. J., Davis, E. E., \& Scerif, G. (2009). Does Colour Preference Have a Role in Colour Term Acquisition? British Journal of Developmental Psychology, 27, 993-1012. https://doi.org/10.1348/026151008X399916

Schloss, K. B., \& Palmer, S. E. (2017). An Ecological Framework for Temporal and Individual Differences in Color Preferences. Vision Research, 141, 95-108. https://doi.org/10.1016/j.visres.2017.01.010

Vygotsky, L. S. (1978). Mind in Society: The Development of Higher Psychological Processes. Cambridge, MA: Harvard University Press.

Zemach, I. K., \& Teller, D. Y. (2007). Infant Color Vision: Infants' Spontaneous Color Preferences Are Well Behaved. Vision Research, 47, 1362-1367.

https://doi.org/10.1016/j.visres.2007.02.002 


\section{Appendix}

\section{Appendix 1}

\section{Color Questionnaire-The Early Childhood Education Classroom}

1) How many different colors do you see at the child's eye level at the entry door of the classroom?

2) Is the classroom visually over stimulating or visually under stimulating? Is color contributing to the visual stimulation in the classroom?

3) Are the walls and ceilings designed with additional materials that cover the surfaces or are there ambient space on the surfaces to give the eye relief from texture and color?

4) Is the child-scaled furniture neutral in color or bright in color?

5) Do the classroom walls have background color? If so, how many walls have background color and is the background color bright, muted, dark, or light?

6) Does the classroom floor have color? Is the color bright, muted, dark, or light? Are there different surface materials for the floor?. If so, what are the different colors for those surfaces materials?

7) Is there color on built-in architectural elements in the space including cabinetry, doors, door casing, baseboard, and window frames?

8) Is there color on display areas or murals? Are the colors bright, muted, dark, or light?

9) How does the natural light from the exterior windows and/or skylights impact the perception of color in the classroom? Is there glare? Are there shadows?

10)How does the artificial or electric lighting contribute to the color in the classroom?

11)Is there task lighting and general lighting? How do these change the color in the classroom?

12)How is the placement of objects in the space affecting the perception of color in the space? Is an object against a wall or is there circulation around the object?

13)What are the surface finishes in the classroom? How does the color appear on the surface finishes? Are they reflective, soft and/or hard?

14)How does the control of natural light (draperies, blinds, shutters, curtains) contribute to the color appearance in the space?

15)Do the draperies, blinds, shutters, or curtains have a color? If so, how is this color perceived?

16) Ask children, parents, and guardians for their experiences with colors in the classroom environment. Their responses are important for understanding how color is perceived in the designed environment. 